\title{
ENZYMATIC MODIFICATION FOR IMPROVING NUTRITIONAL QUALITIES AND ACCEPTABILITY OF PROTEINS EXTRACTED FROM PHOTOSYNTHETIC MICROORGANISMS SPIRULINA MAXIMA AND RHODOPSEUDOMONAS CAPSULATUS ${ }^{1}$
}

\author{
Soichi Arai, Michiko Yamashita, and Masao FuJIMAKI ${ }^{2}$ \\ Department of Agricultural Chemistry, University of Tokyo, \\ Bunkyo-ku, Tokyo 113, Japan
}

(Received April 22, 1976)

\begin{abstract}
Summary The present study attempts to improve the proteins from a blue-green alga Spirulina maxima and a non-sulfur purple bacterium Rhodopseudomonas capsulatus through their peptic hydrolysis followed by plastein synthesis with papain. The former enzymatic process was effective in removing some photosynthetic pigments and flavors originating in the raw materials. The latter process was successful in incorporating limited amounts of methionine, lysine, and tryptophan, and thus to synthesize plasteins whose essential amino acid patterns resemble the FAO/WHO suggested pattern (1973). These plasteins had no colors and no flavors.
\end{abstract}

A worldwide food crisis is going to occur because of increasing human population. At the present rate of increase, the world's current population is expected to double only 35 years from now (1). The securing of sufficient food supplies is a most important problem which must be solved immediately. In developing countries, whose combined population accounts for $70 \%$ of the world's total, agricultural policies have concentrated on increasing food calorie supplies. In addition to calorie shortage, however protein malnutrition is also a serious problem already in most countries in the world (2). Development of new edible protein resources is thus considered to be of pressing importance. Edible things, however, are not necessarily acceptable. Though a new edible protein be developed, it cannot be used for human food unless people will accept it as food. Recently, attention has been paid to the use of photosynthetic resources for food, and their useful values have been assessed (3). Along this line, several studies have been

\footnotetext{
${ }^{1}$ A portion of this paper was presented at the 10th International Congress of Nutrition, Kyoto, August 8, 1975.

2 荒井綜一, 山下道子, 藤巻正生
} 
conducted on blue-green algae $(4,5)$ and a purple bacterium $(6)$ as typical examples of the possible food resources. In the present study, we attempt to improve the nutritional qualities and the acceptability of two kinds of microbial proteins, since they per se are poor in acceptability and nutritive value. The methods of improvement are a series of enzymatic modifications: protein hydrolysis with pepsin, and plastein synthesis with papain. In particular, the present study tries, using our previous methods (7-10), to improve the essential amino acid compositions by incorporating the three limiting amino acids, namely methionine, lysine, and tryptophan, during the plastein synthesis. ${ }^{3}$

\section{MATERIALS AND METHODS}

Starting materials. A spray-dried sample of Spirulina maxima was obtained from Sosa Texcoco S. A., Mexico. Its general composition is: crude protein, $64.2 \%$; crude fat, $5.0 \%$; carbohydrate (as glucose), $16.9 \%$; ash, 6.6\%; and moisture, $4.2 \%$. A freeze-dried sample of Rhodopseudomonas capsulatus was presented by Dr. Michiharu Kobayashi of Kyoto University. Its general composition is: crude protein, 55.5\%; crude fat, 7.5\%; carbohydrate (as glucose), 22.2\%; ash, $2.9 \%$; and moisture, $5.0 \%$.

Preliminary removal of pigments. Each starting material $(10 \mathrm{~g})$ was suspended in $99 \%$ ethanol $(250 \mathrm{ml})$. The suspension was stirred for $3 \mathrm{hr}$ in the dark at room temperature and filtered. The residue was treated similarly with another $250 \mathrm{ml}$ volume of $99 \%$ ethanol. The yields of the ethanol-extractable substance were $2.08 \mathrm{~g}$ from $10 \mathrm{~g}$ of the alga and $2.50 \mathrm{~g}$ from $10 \mathrm{~g}$ of the bacterium.

Protein extraction. Each of the above extraction residues was suspended in $0.1 \mathrm{~N} \mathrm{NaOH}$ (1 liter). The suspension was treated with a mechanical grinder (Dyno-mill $\mathrm{WAB}$ ) at $5^{\circ} \mathrm{C}$ for $30 \mathrm{~min}$ and centrifuged at $10,000 \mathrm{rpm}$ for $20 \mathrm{~min}$. The supernatant was dialyzed with a cellophane tube against running water at $5^{\circ} \mathrm{C}$ until the inner solution became $\mathrm{pH} \mathrm{7.0}$; the time required for this dialysis was approximately $70 \mathrm{hr}$. The nondialyzable fraction was freeze-dried and termed protein A or protein B. Their yields are shown in Table 1.

Enzymes. Twice-crystallized and lyophilized preparations of pepsin (EC 3. 4. 4. 1) and papain (EC 3. 4. 4. 10) were obtained from Sigma Chemical Co. The former was used for the protein hydrolysis and the latter for the plastein synthesis.

Protein hydrolysis. Protein A and protein B were used as substrates and hydrolyzed with pepsin under the following conditions: substrate concentration, $1 \%(\mathrm{w} / \mathrm{v})$ as $\mathrm{N} \times 6.25$; enzyme-substrate ratio, $1: 100(\mathrm{w} / \mathrm{w})$; initial $\mathrm{pH}, 1.5$; incu-

${ }^{3}$ The paper uses the terms protein $\mathrm{A}$, hydrolysate $\mathrm{A}$, and plastein $\mathrm{A}$ for the protein, hydrolysate, and plastein from the alga, and protein B, hydrolysate B, and plastein B for the those from the bacterium. The following abbreviations are used: Met-OEt, Lys-OEt, and Trp-OEt for the ethyl esters of L-methionine, L-lysine , and L-tryptophan, respectively. Also, the term "essential amino acid" is sometimes abbreviated EAA. 
bation temperature, $37^{\circ} \mathrm{C}$; incubation time, $24 \mathrm{hr}$. The resulting degrees of hydrolysis, when measured by using trichloroacetic acid at a final concentration of $10 \%$ (11), were $80.2 \%$ for hydrolysate $\mathrm{A}$ and $77.8 \%$ for hydrolysate $\mathrm{B}$.

Gel filtration. A pair of protein A and hydrolysate $\mathrm{A}$ and a pair of protein B and hydrolysate B were treated with a Sephadex G-15 column. Details for the conditions of elution and the procedures used to investigate the eluted fractions are described in the legends to Figs. 1 and 2.

Color measurement. Optical densities were measured in the range of 250$1200 \mathrm{~nm}$ with a multi-purpose spectrophotometer (Shimadzu APS-50). Details are described in the legends to Figs. 3 and 4.

Plastein synthesis. Hydrolysate A and hydrolysate B fractions after the Sephadex treatment were used as substrate. To the substrate were added Met$\mathrm{OEt} \cdot \mathrm{HCl}$, Lys-OEt $\cdot 2 \mathrm{HCl}$, and $\mathrm{Trp}-\mathrm{OEt} \cdot \mathrm{HCl}$; the amounts added are shown in Table 1. This mixture was subjected to a plastein reaction with papain in the presence of $0.01 \mathrm{M} \mathrm{L}$-cysteine. The conditions were as follows: substrate concentration, $30 \%(\mathrm{w} / \mathrm{v})$ as $\mathrm{N} \times 6.25$; enzyme-substrate ratio, $1: 100(\mathrm{w} / \mathrm{w}) ; \mathrm{pH}, 6.0$; incubation temperature, $37^{\circ} \mathrm{C}$; incubation time, $24 \mathrm{hr}$.

Plastein preparation. An entire incubation mixture after the plastein reaction was diluted with a 100 -fold volume of $10 \%$ ethanol and treated with an Amicon

Table 1. Material balances and protein contents of the products at various stages of the enzymatic process.

\begin{tabular}{|c|c|c|}
\hline Material & $\begin{array}{l}\text { Quantity } \\
\text { by weight } \\
\text { (g) }\end{array}$ & $\begin{array}{c}\text { Protein } \\
\text { content }{ }^{\mathrm{a}} \\
(\%)\end{array}$ \\
\hline \multicolumn{3}{|l|}{ S. maxima } \\
\hline Spray-dried sample ${ }^{b}$ & 10.0 & 64.2 \\
\hline Extracted protein (protein A) & 5.15 & 80.0 \\
\hline Peptic hydrolysate (hydrolysate A) & 4.74 & 83.5 \\
\hline L-Methionine ethyl ester $\cdot \mathrm{HCl}$ added & 0.54 & \\
\hline L-Lysine ethyl ester $\cdot 2 \mathrm{HCl}$ added & 1.18 & \\
\hline L-Tryptophan ethyl ester $\cdot \mathrm{HCl}$ added & 0.10 & \\
\hline Final product (plastein A) & 4.96 & 90.7 \\
\hline \multicolumn{3}{|l|}{ R. capsulatus } \\
\hline Freeze-dried sample ${ }^{b}$ & 10.0 & 55.5 \\
\hline Extracted protein (protein B) & 8.70 & 58.0 \\
\hline Peptic hydrolysate (hydrolysate B) & 3.90 & 64.3 \\
\hline L-Methionine ethyl ester $\cdot \mathrm{HCl}$ added & 0.35 & \\
\hline L-Lysine ethyl ester $\cdot 2 \mathrm{HCl}$ added & 0.65 & \\
\hline L-Tryptophan ethyl ester $\cdot \mathrm{HCl}$ added & 0.04 & \\
\hline Final product (plastein B) & 4.08 & 70.1 \\
\hline
\end{tabular}

a $\mathrm{N} \times 6.25$.

b For the general composition, see the text.

c Hydrolysate treated with the Sephadex G-15 column as shown in Figs. 1 and 2. 
ultrafiltration apparatus equipped with a regulation membrane (UM-05). A fraction having a molecular weight range higher than 500 was thus obtained as a filtration residue which was designated as plastein A or plastein B. The yields of the plasteins are shown in Table 1.

Amino acid analysis. A dried sample $(1 \mathrm{mg})$ in $6 \mathrm{~N} \mathrm{HCl}(1 \mathrm{ml})$ was heated in a de-airated tube at $110^{\circ} \mathrm{C}$ for $20 \mathrm{hr}$. The resulting acid hydrolysate was examined in an amino acid analyzer (Hitachi KLA-4B). Tryptophan was analyzed by another method (12).

Sensory test. Samples in powder were evaluated for their flavor notes and intensities by six panelists from our laboratory.

\section{RESULTS AND DISCUSSION}

The spray-dried sample of $S$. maxima had a dark-green color; the ethanolextractable substance was approximately $20 \%$ of the raw material already mentioned. The sample also had an unfavorable seaweed-like flavor, which was apparently responsible for the low acceptability of the alga. Protein A was brownish in color and still contained the flavor to a certain extent (Table 2). The photosynthetic pigments were not completely separable from protein A, even through treatment with Sephadex (upper chart in Fig. 1). However, when protein A was hydrolyzed with pepsin and then treated with Sephadex, the color fraction was distinctly separated from the protein hydrolysate fraction (lower chart in Fig. 1). It was thus possible to obtain a decolored fraction of hydrolysate $\mathrm{A}$ in a satisfactory yield (Table 1). At the same time, the seaweed-like flavor seemed to have been separated and removed as well (Table 2). On the other hand, the freezedried sample of $R$. capsulatus had a dark-purple color and a fermentation flavor (Table 2). Although even the Sephadex treatment was not effective in completely

Table 2. Colors and flavors of the starting materials and their products at various stages of the enzymatic process.

\begin{tabular}{|c|c|c|c|}
\hline Material or product & Color & Flavor note & $\begin{array}{c}\text { Flavor } \\
\text { intensity }\end{array}$ \\
\hline \multicolumn{4}{|l|}{ S. maxima } \\
\hline Spray-dried sample & Dark green & Seaweed-like flavor & +++ \\
\hline Extracted protein (protein A) & Brownish & Seaweed-like flavor & + \\
\hline Peptic hydrolysate (hydrolysate $\mathbf{A})^{\mathrm{b}}$ & None & Bitter flavor. & ++ \\
\hline Final product (plastein A) & None & Overall flavor & - \\
\hline \multicolumn{4}{|l|}{ R. capsulatus } \\
\hline Freeze-dried sample & Dark purple & Fermentation flavor & ++ \\
\hline Extracted protein (protein B) & Brownish & Fermentation flavor & + \\
\hline Peptic hydrolysate (hydrolysate B) ${ }^{b}$ & None & Bitter flavor & + \\
\hline Final product (plastein B) & None & Overall flavor & - \\
\hline
\end{tabular}

a +++ , strong; ++ , medium; + , weak; - , none.

b Hydrolysate treated with the Sephadex column as shown in Figs. 1 and 2. 
$\leftarrow 10 \%$ Ethanol $\rightarrow 1$

3M. NaCl

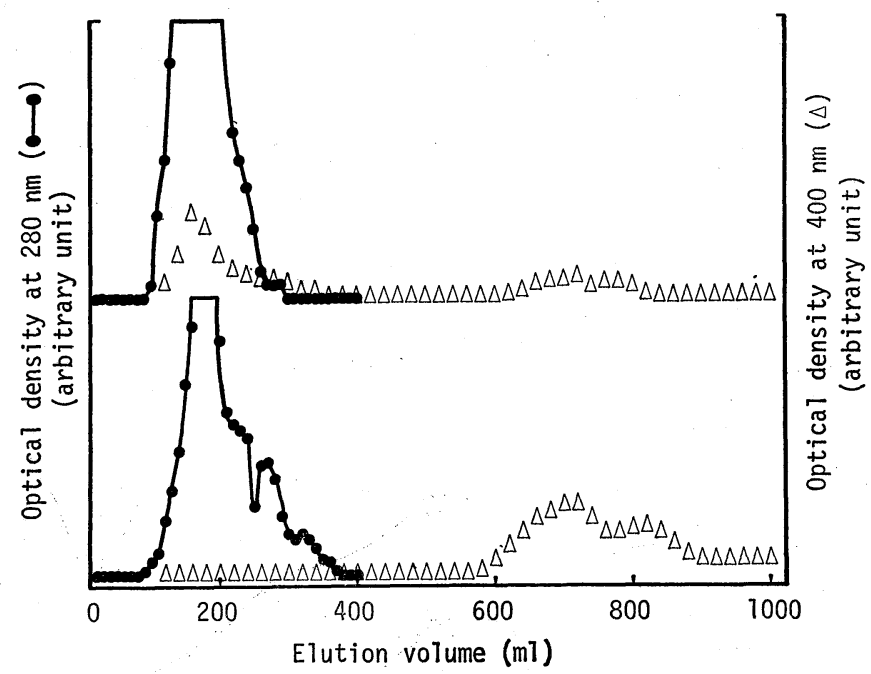

Fig. 1. Elution patterns in gel filtration of the extracted protein a from $S$. maxima (upper) and its peptic hydrolysate ${ }^{\mathrm{b}}$ (lower). Each sample $(0.5 \mathrm{~g})$ put in a Sephadex G-15 column $(3 \times 50 \mathrm{~cm})$ was eluted with $10 \%$ ethanol $(400 \mathrm{ml})$ and with $3 \mathrm{M} \mathrm{NaCl}(600 \mathrm{ml})$ at the rate of $2 \mathrm{ml} / \mathrm{min}$ at room temperature. Every $20-\mathrm{ml}$ aliquot was collected and measured for optical densities at $280 \mathrm{~nm}$ and $400 \mathrm{~nm}$.

a Designated protein A in the text. ${ }^{b}$ Designated hydrolysate $A$ in the text.
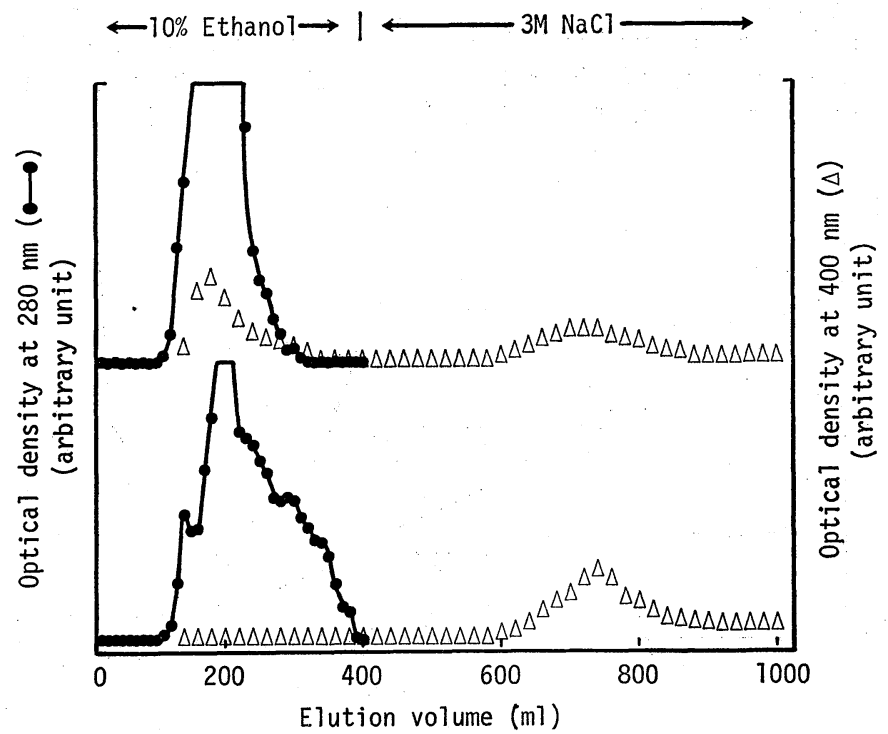

Fig. 2. Elution patterns in gel filtration of the extracted protein ${ }^{2}$ from $R$. capsulatus (upper) and its peptic hydrolysate ${ }^{b}$ (lower). The conditions and procedures are similar to those described in Fig. 1. Designated protein B in the text. $\mathrm{b}$ Designated hydrolysate $B$ in the text. 
removing the pigments from protein B (upper chart in Fig. 2), it was successful in separating them when hydrolysate B was treated similarly (lower chart in Fig.2). Hydrolysate B was found after this treatment to be free from the fermentation flavor as well as from the color (Table 2).

A spectral difference among the Spirulina sample, protein A, and hydrolysate A was obtained; their spectra are indicated respectively with the symbols $\mathbf{S}, \mathbf{P}$, and $\mathrm{H}$ in Fig. 3. In spectrum $\mathrm{S}$ the absorption peaks at 670 and $621 \mathrm{~nm}$ were estimated to be due to chlorophyll a and phycophyllin, respectively. A shoulder

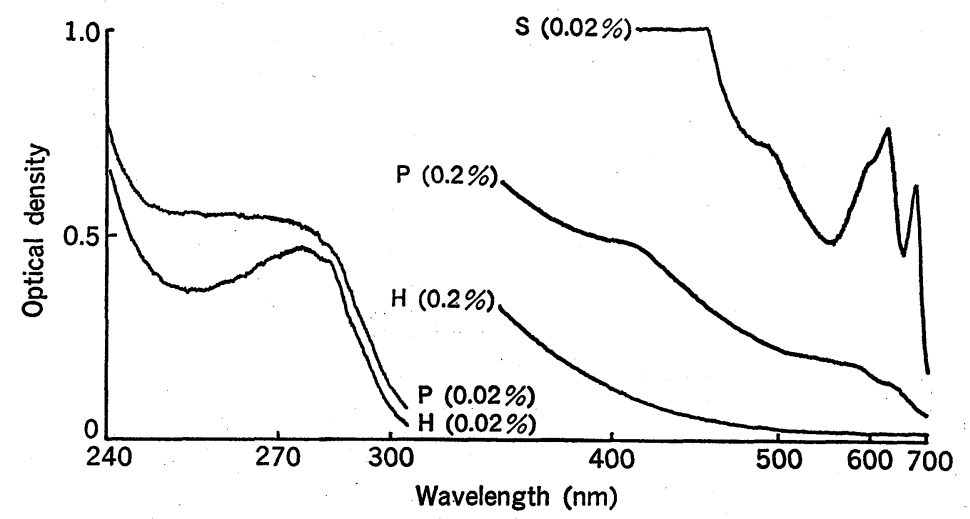

Fig. 3. Absorption spectra of a spray-dried sample of $S$. maxima (S), the extracted protein $^{a}(\mathrm{P})$, and its peptic hydrolysate ${ }^{\mathrm{b}}$ after treatment with Sephadex G-15 (H). Each sample was suspended in $99 \%$ ethanol at a concentration shown in the figure. The spectra were scanned with a Shimadzu multi-purpose spectrophotometer (APS50) at room temperature. a Protein $\mathbf{A}$ in the text. ${ }^{b}$ Hydrolysate $A$ in the text.

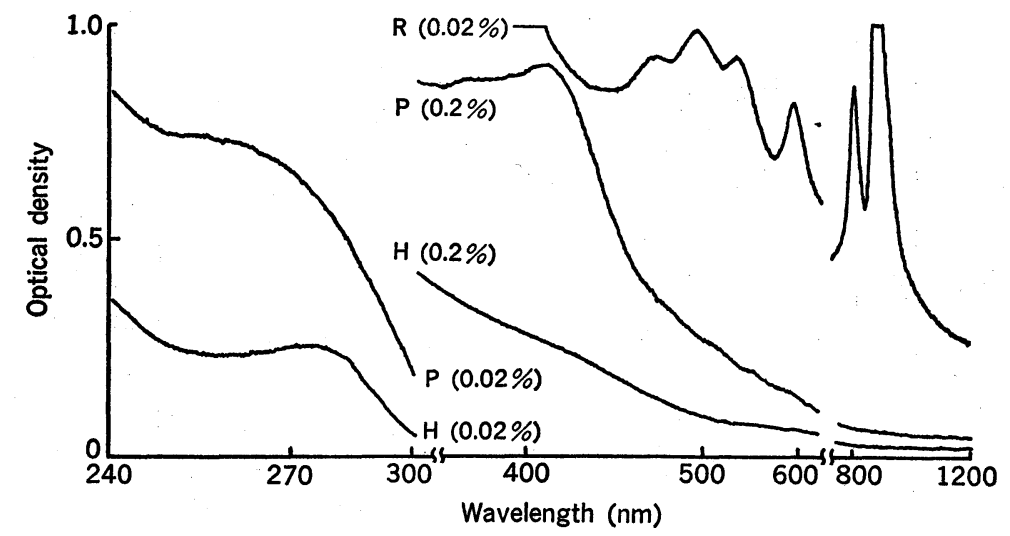

Fig. 4. Absorption spectra of a freeze-dried sample of $\boldsymbol{R}$. capsulatus (R), the extracted protein $^{2}(\mathrm{P})$, and its peptic hydrolysate ${ }^{\mathrm{b}}$ after treatment with Sephadex G-15 (H). The procedures for the measurements are described in Fig. 3. Protein B in the text. $\mathrm{b}$ Hydrolysate $\mathrm{B}$ in the text. 
was observed near $490 \mathrm{~nm}$, indicating the occurrence of carotenoids. Spectrum $\mathbf{P}$ was not so characteristic, although its optical density was much higher than that of spectrum $\mathbf{H}$ throughout the determination range. Spectrum $\mathbf{H}$ had no peaks other than a peak at $278 \mathrm{~nm}$ due to aromatic amino acid residues. A similar difference was found among the spectra $\mathrm{R}, \mathrm{P}$, and $\mathrm{H}$ given by the Rhodopseudomonas sample, protein $\mathrm{B}$, and hydrolysate $\mathrm{B}$, respectively (Fig. 4). Spectrum $\mathrm{R}$ showed strong absorption at 860,797 , and $594 \mathrm{~nm}$, suggesting the presence of bacteriochlorophyll a in this bacterium. The occurrence of several carotenoids was indicated by the peaks arising in the range of $460-540 \mathrm{~nm}$. Spectrum $P$ had no clear-cut peaks; a broad peak near $410 \mathrm{~nm}$ was unidentified. Spectrum $\mathrm{H}$ showed only one peak in the range of $270-280 \mathrm{~nm}$, which was assignable to the peak due to aromatic amino acid residues. These spectral differences are comparable to the differences in apparent color described in Table 2.

As a next step in enzymatic modification, the Sephadex-treated fractions of hydrolysate A and hydrolysate B were subjected to the plastein reaction associated with the EAA incorporation. The membrane filtration and freeze-drying of the plastein reaction mixtures gave plastein $\mathrm{A}$ and plastein $\mathrm{B}$ yields of $49.6 \%$ and $40.8 \%$, respectively (Table 1 ). The material balances, including the amounts of addition of $\mathrm{Met}-\mathrm{OEt} \cdot \mathrm{HCl}$, Lys-OEt $\cdot 2 \mathrm{HCl}$, and $\mathrm{Trp}-\mathrm{OEt} \cdot \mathrm{HCl}$ are shown in Table 1.

Table 3 describes the utilities of the three EAA ethyl esters during the plastein reaction, indicating that they can be utilized at specifically different rates. The specificity of general L-amino acid ethyl esters in their incorporation by papain during the plastein formation from an ovalbumin has been discussed in an earlier paper (13). According to the data given in this discussion, it seems to hold true in general that an amino acid ethyl ester with a more hydrophobic side-chain is more effectively incorporated unless the side-chain contains methyl group branches at the $\beta$-position. Thus the utilities of Lys-OEt, Met-OEt, and Trp-OEt may become better in this order (Table 3).

Table 4 shows the amino acid compositions of protein $\mathrm{A}$ and plastein $\mathrm{A}$ and those of protein B and plastein B. It should be noted that the methionine level

Table 3. Utilities of added L-methionine, L-lysine and L-tryptophan ethyl esters during the plastein synthesis from a peptic hydrolysate of a Spirulina protein (A) and from that of a Rhodopseudomonas protein (B).

\begin{tabular}{lcc}
\hline \multirow{2}{*}{ Amino acid ethyl ester } & \multicolumn{2}{c}{${\text { Utility }(\%)^{a}}^{a}$} \\
\cline { 2 - 3 } & $\mathrm{A}$ & $\mathrm{B}$ \\
\hline L-Methionine ethyl ester & 87.0 & 86.0 \\
L-Lysine ethyl ester & 22.5 & 22.3 \\
L-Tryptophan ethyl ester & 89.9 & 89.7 \\
\hline
\end{tabular}

a $\left\{1-\left(\frac{\text { amount of amino acid ester remaining unreacted }}{\text { amount of amino acid ester added }}\right)\right\} \times 100$. 
has been increased to $8.22 \%$ from $1.37 \%$ in the former case, as a result of the plastein reaction, and to 8.29 from $2.97 \%$ in the latter case. Expected degrees of leveling-up were reached also in the lysine and tryptophan contents (Table 4).

Table 4. Amino acid compositions of a Spirulina protein (protein A) and its plastein (plastein A) and those of a Rhodopseudomonas protein (protein B) and its plastein (plastein B).

\begin{tabular}{|c|c|c|c|c|}
\hline \multirow{2}{*}{ Amino acid } & \multicolumn{4}{|c|}{ Amino acid composition (wt. \%) } \\
\hline & Protein A & Plastein A & Protein B & Plastein B \\
\hline Lysine & 4.59 & 7.75 & 5.37 & 7.39 \\
\hline Histidine & 1.77 & 1.91 & 2.35 & 2.44 \\
\hline Arginine & 6.50 & 6.70 & 6.27 & 6.05 \\
\hline Aspartic acid ${ }^{a}$ & 8.60 & 11.87 & 8.57 & 10.21 \\
\hline Threonine & 4.56 & 5.42 & 5.07 & 4.36 \\
\hline Serine & 4.20 & 4.43 & 3.16 & 4.63 \\
\hline Glutamic acid ${ }^{\mathrm{b}}$ & 12.60 & 14.68 & 10.03 & 9.77 \\
\hline Proline & 3.90 & 3.62 & 4.26 & 3.45 \\
\hline Glycine & 4.75 & 4.76 & 4.53 & 5.98 \\
\hline Alanine & 6.80 & 5.80 & 8.74 & 8.32 \\
\hline Valine & 4.69 & 6.00 & 6.59 & 6.56 \\
\hline Isoleucine & 6.03 & 6.32 & 4.96 & 5.30 \\
\hline Leucine & 8.02 & 8.98 & 8.45 & 8.47 \\
\hline Ar-amino acide & 8.92 & 8.96 & 8.09 & 8.16 \\
\hline Tyrosine & 3.95 & 3.98 & 3.21 & 3.53 \\
\hline Phenylalanine & 4.97 & 4.98 & 4.88 & 4.63 \\
\hline S-amino acid ${ }^{\mathrm{d}}$ & 1.77 & 8.75 & 3.73 & 9.06 \\
\hline$\{$ Methionine & 1.37 & 8.22 & 2.97 & 8.29 \\
\hline$\{$ Half-cystine & 0.40 & 0.53 & 0.76 & 0.77 \\
\hline Tryptophan & 1.40 & 2.72 & 2.05 & 2.56 \\
\hline
\end{tabular}

a Aspartic acid plus asparagine.

b Glutamic acid plus glutamine.

c Aromatic amino acid (tyrosine plus phenylalanine).

d Sulfur-containing amino acid (methionine plus half-cystine).

Incidentally, it may be more interesting to compare the EAA patterns of the four samples with the FAO/WHO-suggested pattern (14) which is considered to be most preferable for human nutrition at present. As shown in Fig. 5, the EAA pattern of protein A was remarkably different from the FAO/WHO pattern, particularly in respect to the methionine, lysine, and tryptophan levels. However, no great difference was found between plastein $\mathrm{A}$ and the FAO/WHO suggestion, as far as the EAA pattern was concerned. Similarly, the EAA pattern of protein B was different from the FAO/WHO pattern, but this difference was effectively lessened by incorporating certain amounts of methionine, lysine, and tryptophan during the plastein synthesis.

From the results of the present study we concluded that the combined pro- 


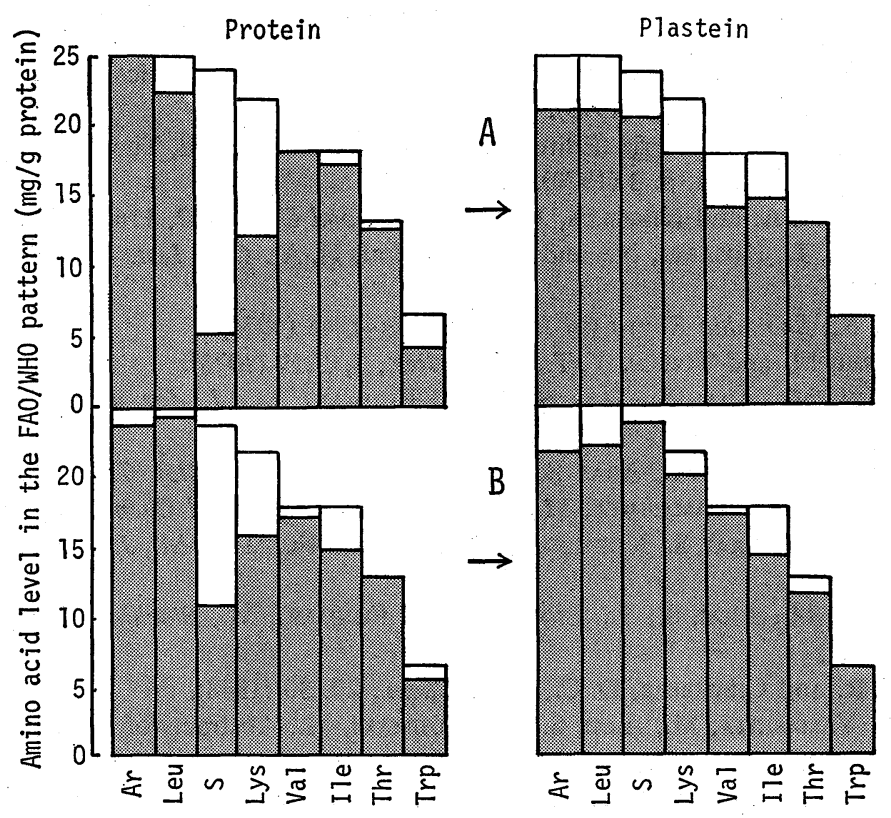

Fig. 5. Essential amino acid $^{a}$ patterns (filled columns) of the extracted protein ${ }^{b}$ from $S$. maxima and its plastein ${ }^{\mathrm{b}}(\mathrm{A})$ and of the extracted protein ${ }^{\mathrm{c}}$ from $R$. capsulatus and its plastein ${ }^{\circ}(\mathrm{B})$. The FAO/WHO suggested patterns are shown (open columns), and their amino acid levels are scaled along the ordinate. a Abbreviations: Ar, aromatic amino acid (i.e., tyrosine plus phenylalanine); $\mathrm{S}$, sulfur-containing amino acid (i.e., methionine plus half-cystine). ${ }^{\mathrm{b}}$ Protein A and plastein A in the text. c Protein B and plastein $B$ in the text.

cesses of two different kinds of enzymatic modification-i. e., protein hydrolysis with pepsin, and plastein synthesis with papain - are useful for effectively removing some non-protein impurities (typified by photosynthetic pigments and flavors) and, at the same time, for reconstituting acceptable and nutritious plasteins from crude protein sources such as photosynthetic microorganisms. In particular, the plastein reaction associated with the simultaneous incorporation of several kinds of EAA can be used as a tool to make up an artificial protein resembling the socalled ideal protein. Further work will be carried out with the plasteins synthesized in the present study, in order to evaluate their nutritive values in vivo. It might also be necessary to continue work on the process proposed in the present paper, in order to determine its economic feasibility.

We wish to express our thanks to Dr. Michiharu Kobayashi of Kyoto University for presenting an R. capsulatus sample, and to Professor Ohki Nakayama of the Yamanashi University for supplying us with an S. maxima sample. We should like to thank also Mr. Ken-ichi Mori of Ajinomoto Co. and Associate Professor Hiroko Kimura of Kagawa Nutrition College for their technical assistance. 


\section{REFERENCES}

1) Hoff, J. E. and JANICK, J., Food (Readings from Scientific American), W. H. Freeman \& Co., San Francisco, p. 183 (1973).

2) AUtret, A., in R. A. Lawrie (Editor), Proteins as Human Food, The AVI Publ. Co., Inc., Westport, Connecticut, p. 3 (1970).

3) Betschart, A. A. and Kinsella, J. E., J. Agr. Food Chem., 22, 116 (1974).

4) Nguyen, H. T., Kosaric, N., and Bergougnou, H. A., Can. Inst. Food Sci. Technol., 7, 114 (1974).

5) OGaWA, R., Shokuhin Kogyo (in Japanese), 17(4), 48 (1974).

6) Kobayashi, M. and Tchan, Y. T., Water Res., 7, 1219 (1973).

7) Yamashita, M., Arai, S., Tsai, S.-J., and Fujimaki, M., J. Agr. Food Chem., 19, 1151 (1971).

8) Aso, K., Yamashita, M., Arai, S., and Fujimaki, M., Agr. Biol. Chem., 38, 679 (1974).

9) Arai, S., Aso, K., Yamashita, M., and Fujimaki, M., Cereal Chem., 51, 143 (1974).

10) Yamashita, M., Arai, S., Kokubo, S., Aso, K., and Fujimaki, M., J. Agr. Food Chem., 23, 27 (1975).

11) Yamashita, M., Arai, S., Tanimoto, S., and Fujimaki, M., Biochim. Biophys. Acta, 358, 105 (1974).

12) Spies, J. R. and Chambers, D. C., Anal. Chem., 20, 30 (1948).

13) Aso, K., Yamashita, M., Arai, S., and Fujimaki, M., Abstracts of Papers, 47th Meeting, Jap. Biochem. Soc., p. 435 (1974).

14) A Report of a Joint FAO/WHO Ad Hoc Expert Committee, Energy and Protein Requirements (in Japanese), Ishiyaku Shuppan, Tokyo, p. 60 (1974). 